NASA/TM-2000-210338

\title{
Rudder/Fin Seal Investigations for the X-38 Re-Entry Vehicle
}

Patrick H. Dunlap, Jr. and Bruce M. Steinetz

Glenn Research Center, Cleveland, Ohio

Donald M. Curry

Johnson Space Center, Houston, Texas

Prepared for the 36th Joint Propulsion Conference and Exhibit cosponsored by AIAA, ASME, SAE, and ASEE Huntsville, Alabama, July 16-19, 2000

National Aeronautics and Space Administration

Glenn Research Center 


\section{Acknowledgments}

The authors greatly acknowledge Jeff Hagen (Lockheed-Martin) for his contributions on the seal design,

Ron Lewis (NASA Johnson Space Center) and Ignacio Norman (Boeing) for their work on the thermal analyses, and Tom Doeberling (NASA Glenn Research Center) for assistance in test support.

Trade names or manufacturers' names are used in this report for identification only. This usage does not constitute an official endorsement, either expressed or implied, by the National

Aeronautics and Space Administration.

NASA Center for Aerospace Information

7121 Standard Drive

Hanover, MD 21076

Price Code: A03
Available from

National Technical Information Service 5285 Port Royal Road Springfield, VA 22100

Price Code: A03 


\title{
RUDDER/FIN SEAL INVESTIGATIONS FOR THE X-38 RE-ENTRY VEHICLE
}

\author{
Patrick H. Dunlap, Jr.* and Bruce M. Steinetz ${ }^{\dagger}$ \\ National Aeronautics and Space Administration \\ Glenn Research Center \\ Cleveland, Ohio 44135 \\ Donald M. Curry ${ }^{\ddagger}$ \\ National Aeronautics and Space Administration \\ Johnson Space Center \\ Houston, Texas 77058
}

\begin{abstract}
NASA is currently developing the $X-38$ vehicle that will be used to demonstrate the technologies required for a crew return vehicle (CRV) for the International Space Station. The X-38 control surfaces require high temperature seals to limit hot gas ingestion and transfer of heat to underlying low-temperature structures to prevent over-temperature of these structures and possible loss of the vehicle.

This paper presents results for thermal analyses and flow and compression tests conducted on as-received and thermally exposed seals for the rudder/fin location of the $\mathrm{X}-38$. A thermal analysis of the rudder/fin dual seal assembly based on representative heating rates on the windward surface of the rudder/fin area predicted a peak seal temperature of $1900^{\circ} \mathrm{F}$. The temperature-exposed seals were heated in a compressed state at $1900{ }^{\circ} \mathrm{F}$ corresponding to the predicted peak temperature. Room temperature compression tests were performed to determine load versus linear compression, preload, contact area, stiffness, and resiliency characteristics for the as-received and temperature-exposed seals. Temperature exposure resulted in permanent set and loss of resiliency in these seals. Unit loads and contact pressures for the seals were below the $5 \mathrm{lb} / \mathrm{in}$. and 10 psi limits set to limit the loads on the Shuttle thermal tiles that the seals seal against in the rudder/fin location. Measured seal flow rates for a double seal were about 4.5 times higher than the preliminary seal flow goal. The seal designs examined in
\end{abstract}

*Mechanical Engineer. Mechanical Components Branch, Member AIAA. tSenior Research Engineer. Mechanical Components Branch,

Member AIAA.

$\ddagger$ Aerospace Technologist, Thermal Branch

Copyright $\odot 2000$ by the American Institute of Aeronautics and Astronautics, Inc. No copyright is asserted in the United States under Title 17. U.S. Code. The U.S. Government has a royalty-free license to exercise all rights under the copyright claimed herein for Governmental Purposes. All other rights are reserved by the copyright owner. this study are expected to be able to endure the high temperatures that they will be exposed to for a single-use life. Tests performed herein combined with future analyses, arc jet tests, and scrubbing tests will be used to select the final seal design for this application.

\section{Introduction}

One of the requirements for putting the manned International Space Station into orbit is the development of a crew return vehicle (CRV) that will serve both as an ambulance for medical emergencies and as an evacuation vehicle. To meet this requirement, NASA is currently developing the $\mathrm{X}-38$ vehicle that will demonstrate the technologies required for the CRV (Fig. la). The X-38 uses a lifting body concept originally developed by the U.S. Air Force's X-24A project in the mid-1960's. ${ }^{1}$ The X-38 also makes use of parachute technology for the landing phase of the return mission previously demonstrated by the Army. Use of this steerable parachute technology for the landing phase eliminates the need for a pilot and simplifies the internal systems of the vehicle. The steerable parachute (parafoil) and control surfaces of the vehicle allow it to reenter autonomously under computer control. By combining the knowledge base from each of these programs and adding expertise gained from the Space Shuttle, the X-38 merges many of the technologies required for the CRV missions.

The $\mathrm{X}-38$ vehicle will be carried into space in the Shuttle cargo bay. It will glide from orbit in an unpowered freefall that is controlled by two movable rudders, two body flaps located at the aft end of the vehicle, and a steerable parafoil deployed after re-entry (Fig. 1). Seal interfaces exist between the movable body flaps and the bottom surface of the vehicle and between the rudders and their respective fins (Figs. $1 \mathrm{a}$ and $1 \mathrm{~b}$ ). These seals must operate hot and limit hot gas ingestion and transfer of heat to underlying low-temperature structures to prevent over-temperature of these structures and possible loss of the vehicle. Development of the body flaps and associated seals is the responsibility of MAN Technologie (Germany). 


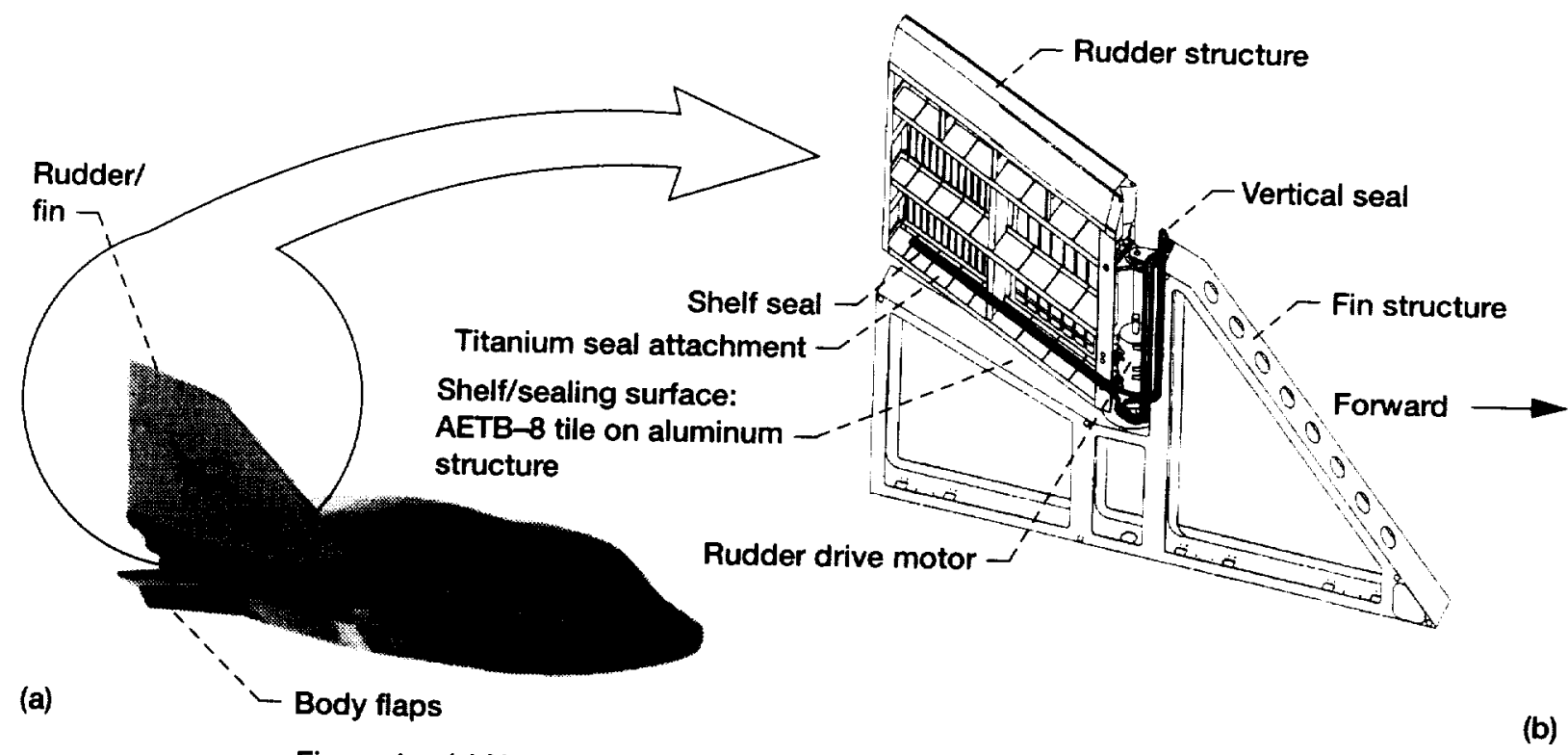

Figure 1.-(a) X-38 vehicle. (b) Rudder/fin structure and seal locations.

NASA's Johnson Space Center (JSC) and Glenn Research Center (GRC) are working together to develop and evaluate the rudder/fin seals.

The specific objectives of the current study are to:

(1) Measure seal flow rates, resiliency, and unit loads both in as-received and temperatureexposed conditions, and

(2) Compare the measured results to property goals where available.

\section{Design Requirements for X-38 Rudder/Fin Seal System}

The design of the X-38 rudder/fin seal assembly consists of a double seal that seals the vertical hinge line and the fin shelf line (Figs. 1 and 2). The vertical seal loop surrounds and protects the rudder drive motor and attachments between the rudder and the fin (Fig. 2). Attached to the surface of the rudder, the seals must allow the rudder to rotate during the entire mission and must accommodate a rudder/fin deflection range of \pm 12 degrees (Fig. 2).

\section{Temperature Limits}

Figure 3 shows a schematic of the rudder/fin seal thermal model and predicted temperatures versus time for the exposed seal and surrounding hardware. Temperature predictions for the exposed seal indicate a peak seal temperature of approximately $1900{ }^{\circ} \mathrm{F}$ (with laminar boundary layer assumption) to $2100^{\circ} \mathrm{F}$ (with turbulent boundary layer assumption) and attachment temperatures of $1500^{\circ} \mathrm{F}$ (Fig. 3b). These peak temperatures occur about $1200 \mathrm{sec}$ (20 min) into re-entry with a subsequent decrease in temperatures for the remainder of the re-entry. Materials used in the seals must be able to withstand these high temperatures. Because the predicted attachment temperature exceeds current adhesive temperature limits, the seals will have to be mechanically attached to the seal attachment bracket and rudder. A detailed discussion of the thermal analysis will be given later in the paper in the section entitled "Thermal Analysis."

\section{Pressure Drop/Preliminary Flow Goal}

The maximum predicted pressure drop across the seal during vehicle re-entry is about $56 \mathrm{lbf} / \mathrm{ft}^{2}$ (outboard: high pressure) and occurs about $450 \mathrm{sec}$ after the peak heating (Fig. 3b). To be conservative, flow tests were conducted up to the peak pressure even though this pressure is not coincident with the peak temperature. As a starting point, designers established a preliminary flow goal through the seal of $4.2 \times 10^{-5} \mathrm{lbm} / \mathrm{sec}$ per inch of seal at a pressure of $56 \mathrm{lbf} / \mathrm{ft}^{2}$.

\section{Resiliency}

No specific design requirement was established a priori for seal resiliency. A main requirement for the seals is that they remain in contact with the sealing surface while the vehicle goes through the maximum re-entry heating cycle. Subsequent to the re-entry heating cycle any small thermally induced gap opening is of no consequence as the convective heating rate drops off sharply.

\section{Seal Loads/Gap}

The seals are to be installed at approximately 20 percent compression to ensure good sealing contact with the rudder/fin surfaces (Fig. 4). The seals will seal 


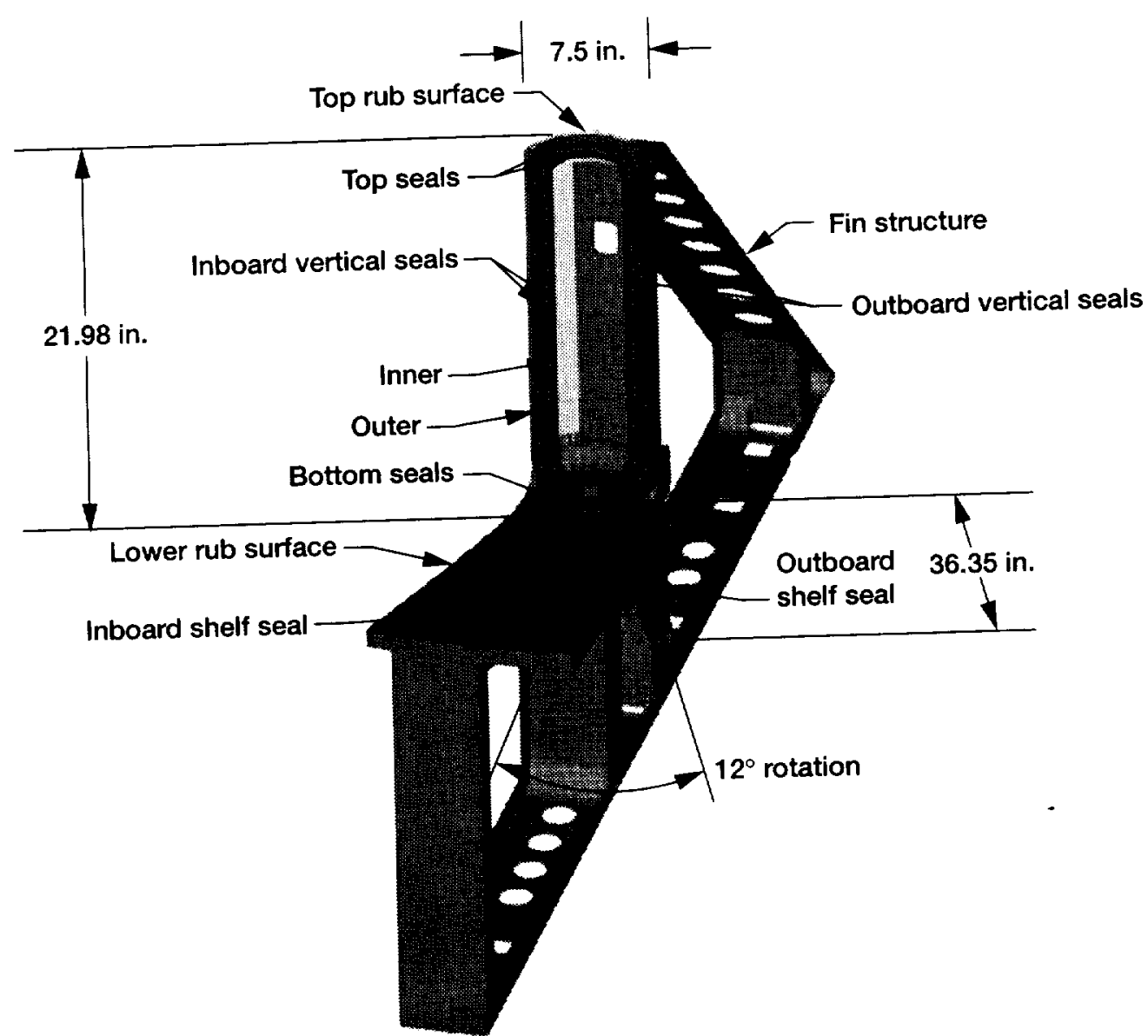

Figure 2.-Computer model depicting rudder/fin seal rotated to full outboard position with seal dimensions.

against Shuttle derived tile which limits the seal unit or contact load. Designers have set a unit load limit of less than 5 pounds per inch of seal to prevent tile damage during installation or actuation. The tiles used for the rudder/fin sealing surfaces are AETB-8 (Alumina Enhanced Themal Barrier $-8 \mathrm{lb} / \mathrm{ft}^{3}{ }^{3}$ density) with Reaction Cured Glass (RCG)/Toughened Uni-Piece Fibrous Insulation (TUF/) coating. A seal unit load of $5 \mathrm{lb} / \mathrm{in}$. with a contact width of 0.50 in. would apply a pressure to the tiles of $10 \mathrm{psi}$. This provides a safety factor of better than four compared to the average through-the-thickness flatwise tensile strength for these tiles of $46 \mathrm{psi}$ (Table 1). If the average through-the-thickness compression strength of $58 \mathrm{psi}$ for the tiles is used in the calculations, a safety factor near six is attained for a unit load of $5 \mathrm{lb} / \mathrm{in}$. The seals are required to seal a nominal 0.25 -in. gap between the surfaces of the rudder and fin.

\section{Life/Wear Resistance}

The $\mathrm{X}-38$ vehicle rudder/fin seals are only required to last for one mission. The seals are expected to be replaceable after each mission.
During the single use mission, the seals will be moved on to and off of the sealing surface as the rudder rotates. They must be robust enough to endure the scrubbing that they will experience in being moved across the sealing surface. They also must not be compromised by the "scissoring" action they will experience as they are moved on to and off of the shelf sealing surface. When the seals are moved off of the fin shelf they will tend to return to an uncompressed shape. As they are moved back on to the surface and compressed again, they must be able to endure the shear forces that they will be subjected to without causing excessive loads on the rudder drive motor.

\section{Test Apparatus and Procedures}

\section{Seal Specimens}

Two seal designs were examined in this study, both with a nominal diameter of 0.62 in. (see Table 2 and Fig. 4). Both designs consisted of an Inconel X-750 spring tube stuffed with Saffil batting and overbraided with two layers of Nextel 312 ceramic fibers. The Inconel wires used in the spring tube were formed from rod that was 


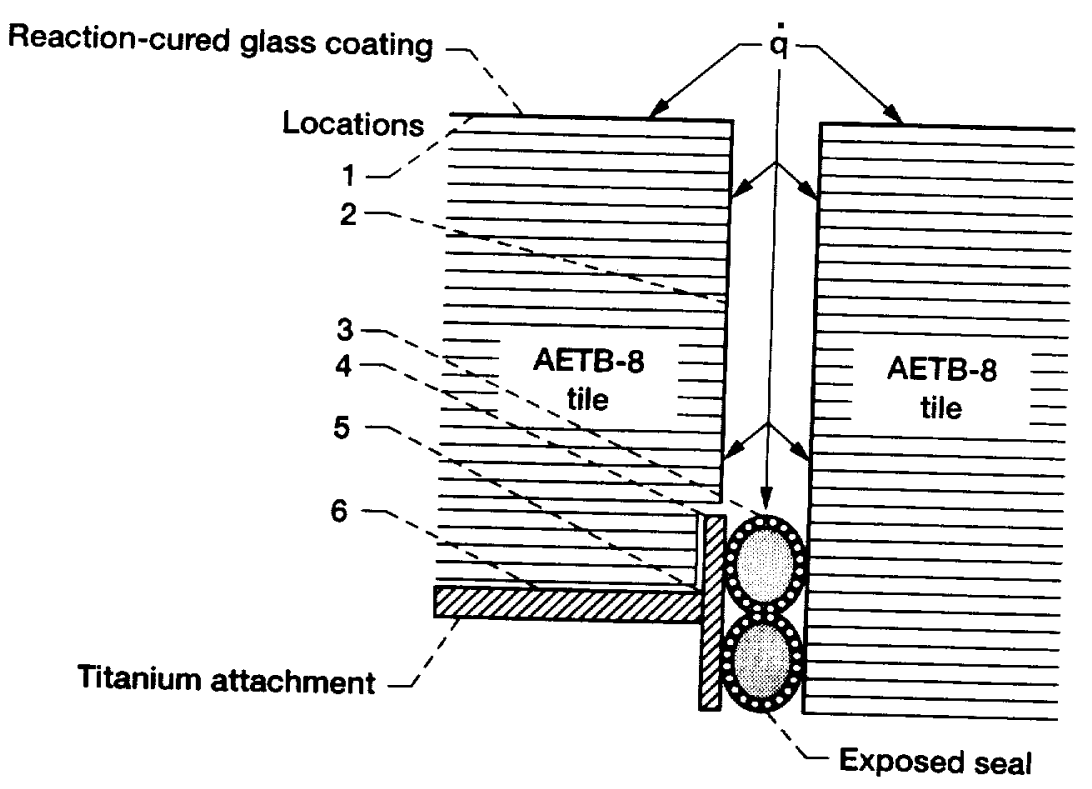

(a)

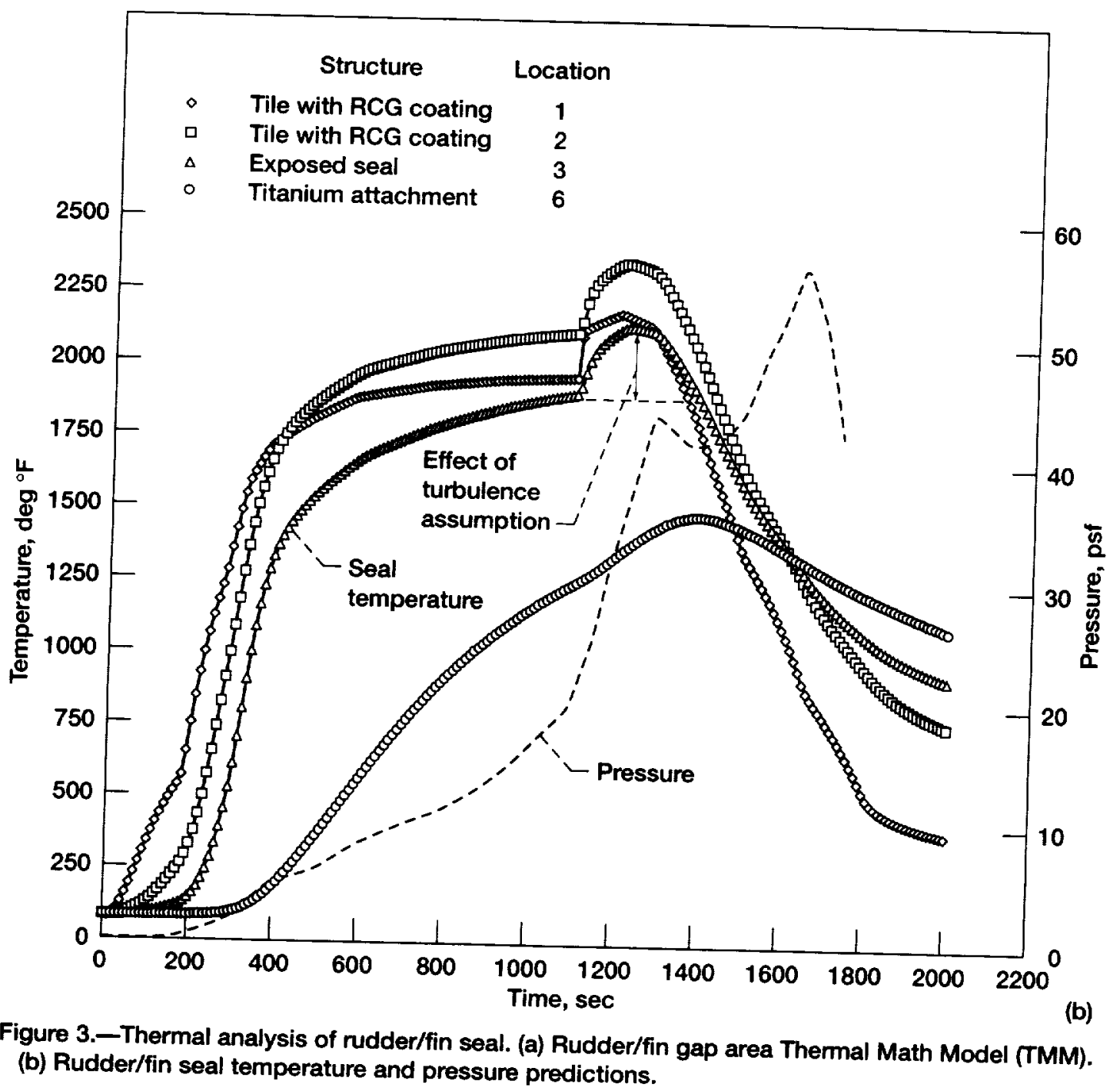




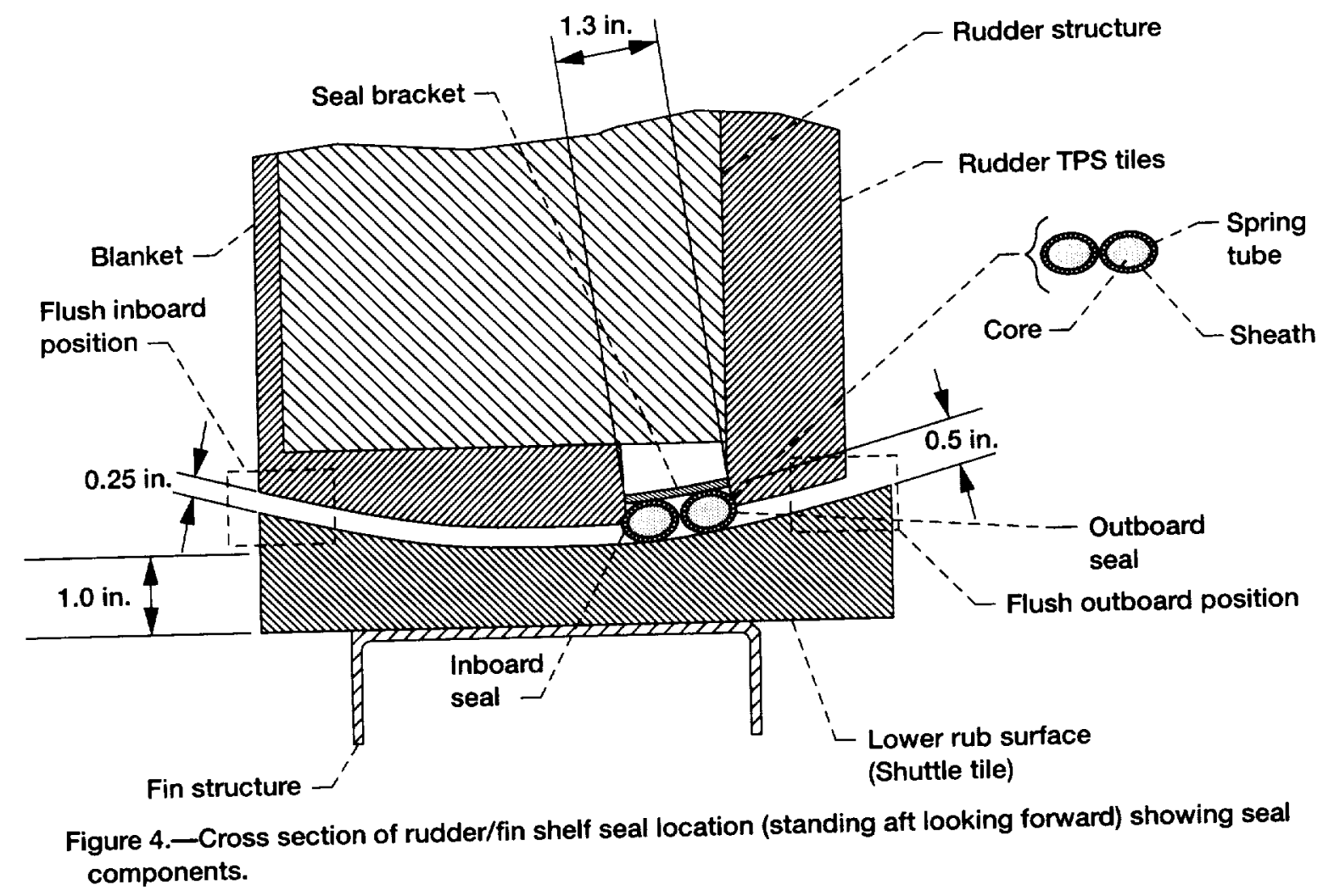

TABLE 1.-MECHANICAL PROPERTIES OF AETB-8 SHUTTLE TILE

\begin{tabular}{|c|c|c|c|}
\hline Material & $\begin{array}{c}\text { Average through-the-thickness } \\
\text { flatwise tensile strength } \\
(\mathrm{psi})\end{array}$ & $\begin{array}{c}\text { Average through-the-thickness } \\
\text { compression strength } \\
\text { (psi) }\end{array}$ & $\begin{array}{c}\text { Average weak direction } \\
\text { shear strength } \\
\text { (psi) }\end{array}$ \\
\hline AETB-8 & 46 & 58 & 54 \\
\hline
\end{tabular}

Data provided courtesy of Boeing North American, Inc., Reusable Space Systems.

TABLE 2-X-38 SEAL CONSTRUCTION MATRIX

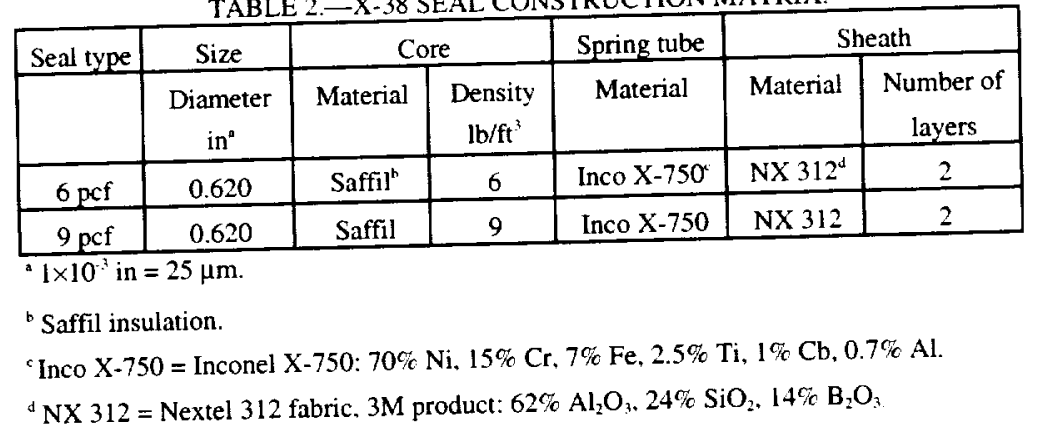

previously annealed at $2100^{\circ} \mathrm{F}$ or higher in a non-nitriding atmosphere. The primary difference between the two designs was the density of the Saffil battings that were stuffed into the Inconel spring tube. One design had a $6 \mathrm{lb} /$ $\mathrm{ft}^{3}$ batting in its core (hereafter referred to as the 6 pcf design), while the other design used a $9 \mathrm{lb} / \mathrm{ft}^{3}$ batting ( 9 pcf design). The primary seal tested in this study was the $6 \mathrm{pcf}$ design. A full battery of compression and flow tests was conducted on this design (Table 3 ). Selected tests were conducted on the 9 pcf design for comparison purposes. Each test listed in the test matrix was performed on a separate seal specimen. 
TABLE 3.-TEST MATRIX FOR X-38 RUDDER/FIN SEAL TESTING.

Checked blocks indicate tests performed

Compression Testing
\begin{tabular}{|l|c|c|c|c|c|c|}
\hline Compression level & \multicolumn{2}{|c|}{$20 \%$} & \multicolumn{2}{c|}{$25 \%$} & \multicolumn{2}{c|}{$30 \%$} \\
\hline & Primary & Repeat & Primary & Repeat & Primary & Repeat \\
\hline 6 pcf as-received & $\checkmark$ & $\sqrt{ }$ & $\checkmark$ & $\sqrt{ }$ & $\sqrt{ }$ & $\checkmark$ \\
\hline 6 pcf after time at $1900 \mathrm{deg} F$ & $\downarrow$ & $\sqrt{ }$ & $\sqrt{ }$ & $\sqrt{ }$ & $\checkmark$ \\
\hline 9 pcf as-received & $\downarrow$ & $\sqrt{ }$ & & & & \\
\hline
\end{tabular}

Flow Testing

\begin{tabular}{|c|c|c|c|c|c|c|c|c|}
\hline Gap size & \multicolumn{4}{|c|}{$0.25 \mathrm{in}$} & \multicolumn{4}{|c|}{0.13 in } \\
\hline \multirow[t]{2}{*}{ Compression level } & \multicolumn{2}{|c|}{$20 \%$} & \multicolumn{2}{|c|}{$25 \%$} & \multicolumn{2}{|c|}{$20 \%$} & \multicolumn{2}{|c|}{$25 \%$} \\
\hline & Primary & Repeat & Primary & Repeat & Primary & Repeat & Primary & Repeat \\
\hline \multicolumn{9}{|l|}{ Single Seal } \\
\hline 6 pef as-received & $\sqrt{ }$ & $\sqrt{ }$ & $\checkmark$ & & $\sqrt{i}$ & & $\checkmark$ & \\
\hline $6 \mathrm{pcf}$ after time at $1900 \mathrm{deg} F$ & $\sqrt{ }$ & $\sqrt{ }$ & $\sqrt{ }$ & & $\sqrt{ }$ & & $\sqrt{ }$ & \\
\hline 9 pcf as-received & $\sqrt{ }$ & $\sqrt{4}$ & & & & & & \\
\hline \multicolumn{9}{|l|}{ Double Seal } \\
\hline 6 pcf as-received & 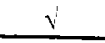 & & & & & & & \\
\hline
\end{tabular}

The seals examined in this study are currently used in several places on the Space Shuttle orbiters. They seal the main landing gear doors, the orbiter external tank umbilical door, and the payload bay door vents. These seals were selected as the baseline seal design for the rudder/fin location of the X-38.

\section{Thermal Analysis}

Figure 3 shows a schematic of the rudder/fin gap area Thermal Math Model (TMM) and predicted temperatures for the exposed seal and surrounding hardware. The TMM is a quasi-two-dimensional representation built using the System Improved Numerical Differencing Analyzer (SINDA) V3.1 and consists of approximately 150 nodes that represent the Thermal Protection System (TPS) tiles, the dual seals, and the titanium attachment structure (Fig. 3a). The TPS material on both the rudder and the fin is modeled as RCG/TUFI coated AETB- 8 tile. The seal is modeled as Nextel 312 fabric over Saffil batting $\left(6 \mathrm{lb} / \mathrm{ft}^{3}\right)$. The seal attachment is modeled as a solid titanium structure. For each material, temperature dependent and pressure dependent ( where required) properties are used. All modes of heat transfer (i.e., conduction, convection, and radiation) were accounted for in the model. The model did not, however, include the effects of flow through the seal. The Thermal Synthesizer System (TSS) was used to resolve the radiation exchange between all exposed surfaces inside and outside of the gap including radiation to space. Results from the TSS analysis were coupled to the SINDA analysis program. The gap is modeled as being 1.5 in. deep and 0.25 in. wide. All connections between dissimilar materials are assumed to be perfect, i.e. no contact resistance is modeled.
The surface heating used to drive this TMM was based on Cycle 8 reference heating and was supplied by the Johnson Space Center Aeroscience and Flight Mechanics Division (EG/W. Goodrich). The heating supplied is representative of the heating predicted on the windward surface of the rudder/fin area. The heating distribution within the gap was determined using the gap heating relationship presented by Nestler.2 Nestler's empirical relationship provides for the heat flux to a certain gap depth (e.g., to the seal) and assumes no flow through the floor of the gap (e.g., an impermeable seal). The authors recognize that with flow through the seal the maximum seal temperatures may be slightly higher than those shown in Fig. 3b.

\section{Temperature Exposure Tests}

The thermal analysis predicted that the rudder/fin seals will be exposed to temperatures at or above $1900^{\circ} \mathrm{F}$ during re-entry of the $\mathrm{X}-38$ vehicle. To simulate exposure to such extreme temperatures and to determine the effects that this exposure has on the seals, specimens were placed into a tube furnace in a compressed state and heated at $1900^{\circ} \mathrm{F}$ for seven minutes. This seven-minute temperature exposure closely simulates the amount of time that the seals will spend at the peak temperature during re-entry (Fig. 3b). For the present study, only the 6 pcf seal design was temperature exposed.

In each test, a 1-ft-long seal specimen was clamped into a fixture between two flat stainless steel plates and subjected to a linear compression of 20,25 , or 30 percent of its overall diameter of $0.62 \mathrm{in}$. Spacers between the plates controlled the amount of compression applied to each specimen. The fixture with the specimen compressed 
inside of it was placed into the tube furnace at room temperature. A thermocouple inside the furnace measured the temperature of the specimen throughout the test. The furnace was programmed to heat the specimen to $1900^{\circ} \mathrm{F}$ and hold it at that temperature. After seven minutes at $1900^{\circ} \mathrm{F}$, the fixture and specimen were removed from the furnace and allowed to cool at room temperature. For reference purposes, it took an average of about 95 minutes for the specimen and clamping fixture temperatures to rise from $1200^{\circ} \mathrm{F}$ to $1900^{\circ} \mathrm{F}$. Once the fixture and specimen cooled down, the fixture was opened up, and the specimen was removed. Specimens were then subjected to flow and compression tests to examine the effects that the temperature exposure had on the permeability, stiffness, and resiliency of these seals, as outlined in Table 3.

\section{Compression Tests}

Compression tests were performed to determine seal preload and resiliency behavior at room temperature using a precision linear slide compression test fixture shown schematically in Fig. 5. A specimen was loaded into a stationary grooved specimen holder, and an opposing plate was compressed against the specimen. The groove was rectangular in shape with a width of 0.62 in. and a depth of $0.37 \mathrm{in}$. Stainless steel shims were placed in the groove behind the specimen to vary the amount of linear compression. Specimens of 1.5 to 3 in. long were tested. Specimen lengths were chosen to stay within the combined $10 \mathrm{lb}$. load limit of the two $5 \mathrm{lb}$. load cells on the fixture. Longer specimens were used for tests in which the compression forces were expected to be low. The amount of compressive load on the specimen was measured versus the amount of linear compression for several load cycles. Multiple load cycles were applied to the specimen before

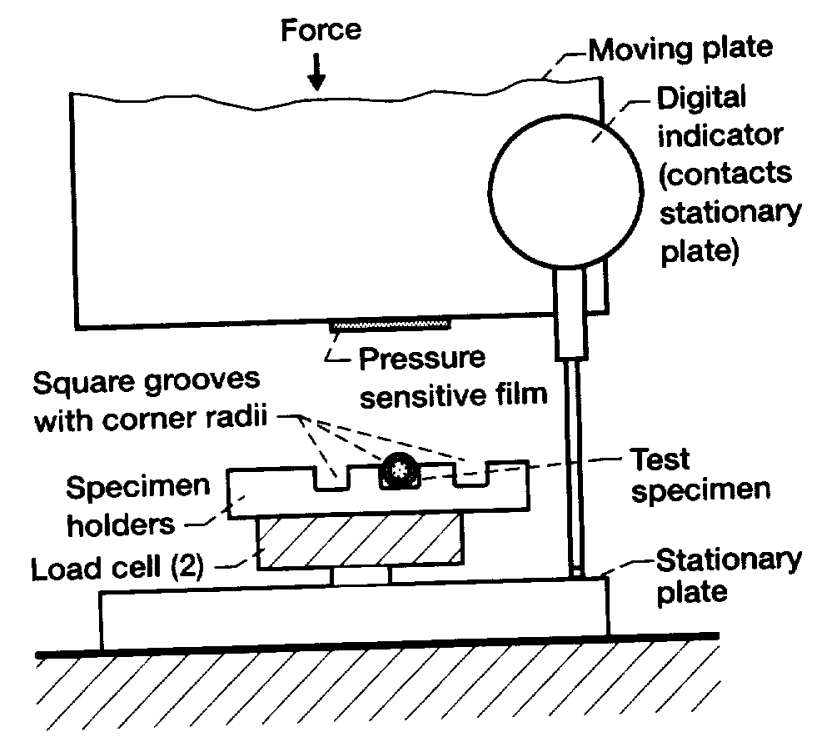

Figure 5.-Schematic of compression fixture. the preload data point was recorded to remove the effects of hysteresis and permanent set that accumulate with load cycling of the specimens. Most permanent set occurred within the first four load cycles, so each test lasted for four cycles. A pressure sensitive film mounted on the opposing plate was used to determine the contact width of the specimen as it was compressively loaded. The footprint length and width at the end of the fourth load cycle were used to calculate seal preload in pounds per square inch. The measured load versus compression data was used to determine residual interference corresponding to a given linear crush value. ${ }^{3}$ Residual interference is defined as the distance that the specimen will spring back while maintaining a load of at least $0.01 \mathrm{lb} / \mathrm{in}$. of specimen. The hardware and procedure used to perform these tests are described in detail by Steinetz et al. ${ }^{3}$ Overall accuracy of the preload values measured using this method was calculated to be \pm 3.4 percent of the value. ${ }^{4}$

Test Matrix-Compression tests were performed to determine the specimen preloads corresponding to the linear crushes used in the flow experiments. Tests were conducted on the $6 \mathrm{pcf}$ seal design at compression levels of 20,25 , and 30 percent of the specimen's overall diameter (Table 3 ). Primary and repeat compression tests were performed. Primary and repeat tests were performed on the 9 pcf design at 20 percent compression. A series of tests were also conducted on specimens of the 6 pcf seal design after temperature exposure. These specimens were temperatureexposed and compression tested at compression levels of 20 , 25 , or 30 percent. Primary and repeat tests were performed at all three compression levels.

\section{Flow Tests}

Flow tests were performed on the seals in an ambient temperature linear flow fixture shown schematically in Fig. 6. The flow fixture was designed so that either single or double seals of different diameters could be tested in removable cartridges that are inserted into the main body of the test fixture. Seals can be tested in this fixture with different seal gaps and under different amounts of linear compression.

Flow Path/Instrumentation-During flow testing, pressurized air enters through an opening in the base of the fixture and passes through a plenum chamber before reaching the test seal. Air flows through the gap between the cartridge and the cover plate, passes through the seal, and then flows out of the top of the fixture (Fig. 6a). A flow meter upstream of the flow fixture measures the amount of flow that passes through the test seal. The flow meter has a range of 0 to 100 standard liters per minute ( 0 to $4.5 \times 10^{-3} \mathrm{lbm} / \mathrm{sec}$ ) and an accuracy of 1 percent of full scale. A pressure transducer ( 0 to 5 psid, 0.07 percent accuracy) upstream of the test seal measures the differential pressure across the seal, and a thermocouple measures the upstream temperature. 

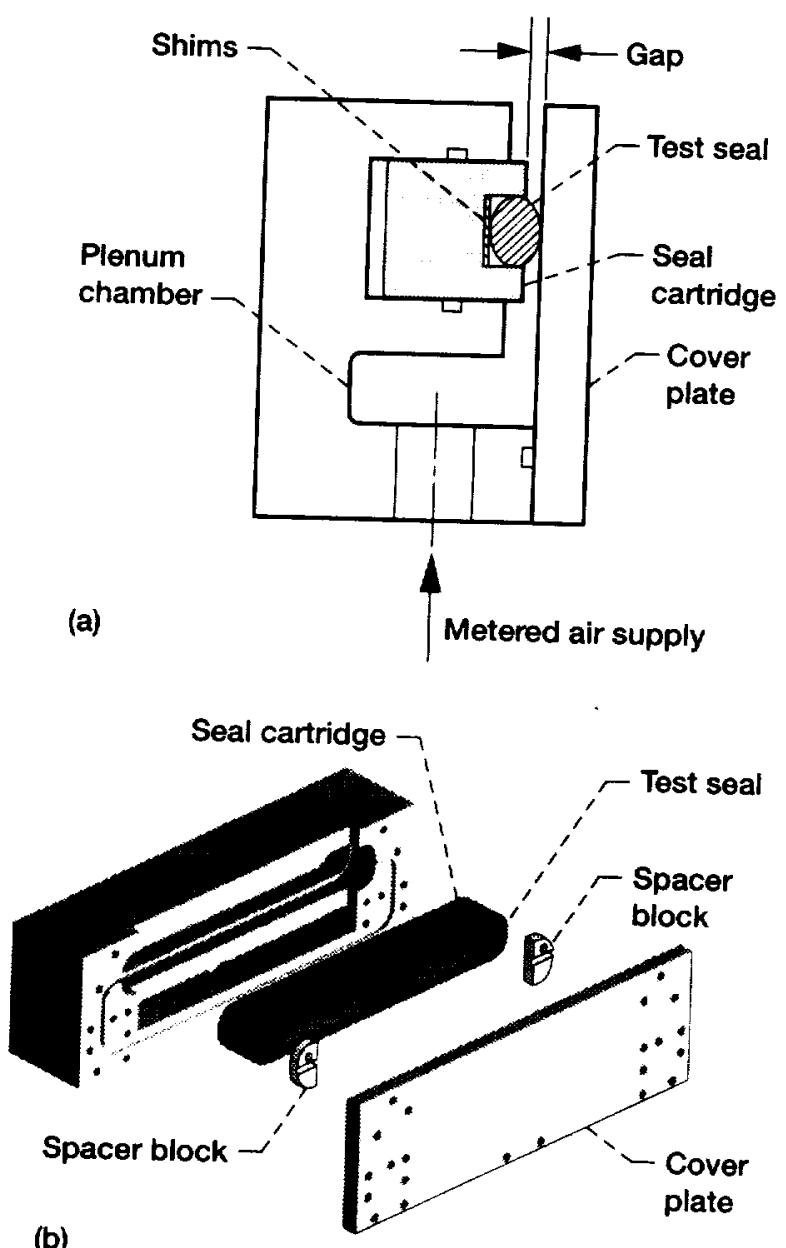

(b)

Figure 6.-Schematic of flow fixture. (a) Cross section. (b) Isometric.

Test Fixture-Test seals of approximately 12 in. in length are mounted in the groove of a cartridge in a linear configuration. The rectangular groove has a width for a single seal of 0.62 in. and a width for a double seal of $1.30 \mathrm{in}$. The amount of preload, or linear compression, is varied by placing steel shims in the cartridge groove behind the seal. For tests performed at 20 percent compression, the groove depth of 0.25 in. is the same as the groove depth used for the X-38 rudder/fin seal application (Fig. 4). The cartridge is inserted into the test fixture. An O-ring seals the perimeter of the cartridge chamber to prevent flow from passing behind the cartridge during testing. Pairs of spacer blocks secured to the cartridge at the ends of the test specimen control the gap width between the cartridge and the cover plate that the seals seal against (Fig. 6b). Blocks of different thicknesses are used to vary the gap width. A small amount of RTV is placed between each spacer block and the cartridge to prevent flow from passing through this gap. Another
O-ring is placed in a groove on the surface of the test fixture and into a groove in the spacer blocks to seal the plenum chamber upstream of the test seal. The ends of this $\mathrm{O}$-ring are pressed up against the ends of the test seal to prevent flow from passing around the ends of the seal. End effect leakage is minimized by exposing only the center $10 \mathrm{in}$. of the seal to the prescribed gap. One inch at each end of the 12-in. test specimen is embedded into the fixture (i.e., gap width is zero) to reduce the effects of flow passing between the seal ends and the O-ring. Preload is applied to the test seal through an interference fit between the seal and the cover plate.

Test Matrix - Tests were conducted on the as-received 6 pcf seal design at compression levels of 20 and 25 percent of the specimen's overall diameter for gap sizes of 0.25 in. and 0.13 in. (Table 3) Primary flow tests were performed for all of these combinations, and a repeat test was performed at 20 percent compression with a 0.25 -in. gap to examine the repeatability of the tests. A double seal test was performed at 20 percent compression with a 0.25 -in. gap. Primary and repeat tests were performed on the as-received $9 \mathrm{pcf}$ design at 20 percent compression for a 0.25 -in. gap. A series of tests were also conducted on the $6 \mathrm{pcf}$ design after temperature exposure. These specimens were temperature-exposed and flow tested at compression levels of 20 or 25 percent. Primary tests were performed at 20 and 25 percent compression for both gap sizes, and a repeat test was performed at 20 percent compression for a 0.25 -in. gap.

\section{Results and Discussion}

\section{Temperature Exposure Test Results}

The temperature exposure tests conducted on the $6 \mathrm{pcf}$ seal design caused a distinct change in the shape and properties of these seals. After temperature exposure at $1900^{\circ} \mathrm{F}$ while compressed between two steel plates, the seal specimens did not return to their original circular cross section. They took on an elliptical cross section that was quite flat in the areas that were in contact with the plates (Fig. 7a). The specimens were stiffer and much less flexible than they were before the temperature exposure.

Most of these changes are believed to be due to changes that occurred in the Inconel X-750 spring tube. The Inconel X-750 spring tube that contributes significantly to the resiliency of the seals appeared to have taken on a large permanent set. This behavior makes sense since the yield strength of Inconel X-750 at $1900^{\circ} \mathrm{F}$ is less than 5 percent of its room temperature strength. ${ }^{5}$ The yield strength of the Inconel wires dropped steadily as the specimens were heated from 1200 to $1900^{\circ} \mathrm{F}$. This prevented the seal from returning to its original circular cross section and caused it to take on the new elliptical cross section. 

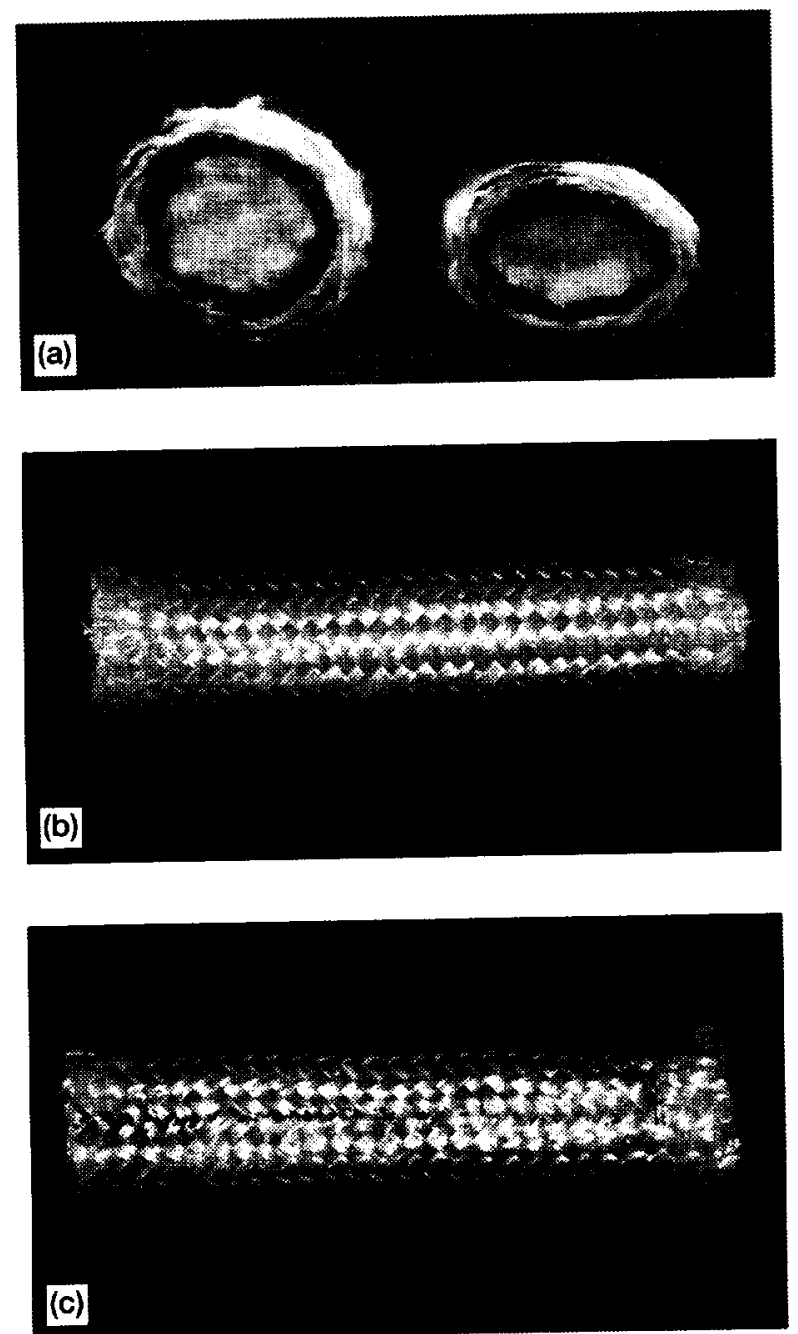

Figure 7.-Photos of 6 pcf $X-38$ seals before and after $1900^{\circ} \mathrm{F}$ temperature exposure. (a) Side-byside photo of seals before (left) and after (right) temperature exposure. (b) Photo of seal before exposure showing condition of ceramic outer layer. (c) Photo of seal after exposure showing condition of ceramic outer layer.
The Nextel 312 ceramic fabric that formed the outermost layers of the seals did not undergo any noticeable changes during these tests. The ceramic fibers remained white in color with no macroscopic signs of damage (Figs. $7 \mathrm{~b}$ and $7 \mathrm{c}$ ) and no obvious differences in flexibility. This behavior is consistent with the manufacturer's continuous use temperature rating for Nextel 312 of $2200^{\circ} \mathrm{F}$. ${ }^{6}$ Some of the specimens did have black deposits left on them in the areas that were in contact with the stainless steel plates. This was due to oxidation of the steel at these high temperatures. However, these deposits flaked off rather easily and were removed from the specimens before additional tests were performed on them. The Saffil batting that formed the core of the seals also appeared unchanged. The Saffil batting material has a continuous use temperature of $2000^{\circ} \mathrm{F}$ and a single use temperature of $2600{ }^{\circ} \mathrm{F}^{7}$ Because the seals that are to be used in the $\mathrm{X}-38$ are designed to be replaceable, the single use temperature limit applies, indicating that the batting meets the requirement. Further discussions of the specific changes to seal flow rates, resiliency, and stiffness due to $1900^{\circ} \mathrm{F}$ exposure will be addressed in the following sections.

\section{Compression Test Results}

Table 4 summarizes the results of the compression tests performed on the 6 pcf seal design in the as-received condition and after temperature exposure and on the 9 pcf design in the as-received condition. Values listed in this table include the measured residual interference, contact width, unit load, preload, and seal stiffness for each amount of linear compression at which the tests were performed. Figure 8 shows the load versus displacement characteristics for the $6 \mathrm{pcf}$ seal in the as-received condition and after temperature exposure for a linear compression of 0.124 in. ( 20 percent compression). This figure is typical of the type of data that is recorded from compression tests on the X-38 seals in the as-received condition and after temperature exposure. It shows that the load versus

TABLE 4.-X-38 SEAL RESIDUAL INTERFERENCE, CONTACT WIDTH, UNIT LOAD.

PRELOAD AND STIFFNESS FOR SEVERAL LINEAR CRUSH CONDITIONS.

\begin{tabular}{|c|c|c|c|c|c|c|c|c|c|}
\hline Seal type & Condition & $\begin{array}{c}\text { Diameter, } \\
\text { in }\end{array}$ & $\begin{array}{c}\text { Nominal } \\
\text { compression level. } \\
\%\end{array}$ & $\begin{array}{c}\text { Linear } \\
\text { compression, } \\
\text { in }\end{array}$ & $\begin{array}{c}\text { Residual } \\
\text { interference, } \\
\text { (springback) } \\
\text { in }\end{array}$ & $\begin{array}{l}\text { Contact } \\
\text { width, } \\
\text { in }\end{array}$ & $\begin{array}{l}\text { Unit load, } \\
\text { lbf/in }\end{array}$ & $\begin{array}{c}\text { Preload. } \\
\text { psi }\end{array}$ & $\begin{array}{c}\text { Stiffness }(\mathrm{k}) \text { at } \\
\mathcal{F}_{0} \text { linear crush. } \\
\text { lbf/in }\end{array}$ \\
\hline $6 \mathrm{pcf}$ & As-received & 0.620 & $\begin{array}{l}20 \\
25 \\
30 \\
\end{array}$ & $\begin{array}{l}0.124 \\
0.155 \\
0.186 \\
\end{array}$ & $\begin{array}{l}0.084 \\
0.115 \\
0.118 \\
\end{array}$ & $\begin{array}{l}0.455 \\
0.581 \\
0.692 \\
\end{array}$ & $\begin{array}{l}2.01 \\
2.98 \\
4.47 \\
\end{array}$ & $\begin{array}{l}4.4 \\
5.1 \\
6.4\end{array}$ & $\begin{array}{l}39 \\
51 \\
66 \\
\end{array}$ \\
\hline $6 \mathrm{pcf}$ & $\begin{array}{l}\text { After } 1900 \mathrm{~F} \\
\text { exposure }\end{array}$ & 0.620 & $\begin{array}{l}20 \\
25 \\
30 \\
\end{array}$ & $\begin{array}{l}0.124 \\
0.155 \\
0.186 \\
\end{array}$ & $\begin{array}{l}0.018 \\
0.036 \\
0.029 \\
\end{array}$ & $\begin{array}{l}0.379 \\
0.452 \\
0.489 \\
\end{array}$ & $\begin{array}{l}0.91 \\
1.77 \\
1.90 \\
\end{array}$ & $\begin{array}{l}2.4 \\
3.9 \\
3.9 \\
\end{array}$ & $\begin{array}{r}58 \\
76 \\
106 \\
\end{array}$ \\
\hline $9 \mathrm{pcf}$ & As-received & 0.620 & 20 & 0.124 & 0.080 & 0.495 & 2.43 & 4.9 & 52 \\
\hline
\end{tabular}




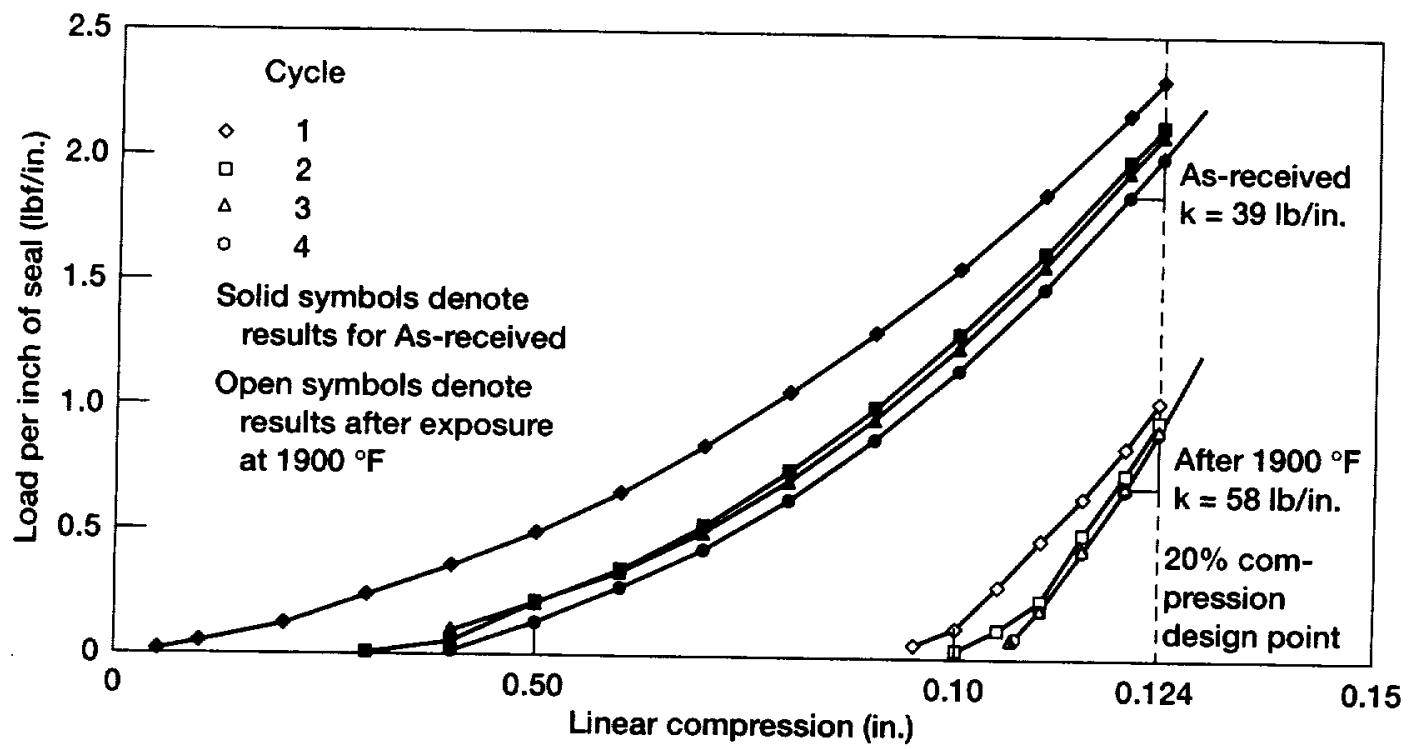

Figure 8.-Load versus linear compression data for four cycles, 6 pcf seal before and after $1900^{\circ} \mathrm{F}$ exposure at representative compression of 0.124 in (20\%).

displacement curves for each load cycle converge upon each other as the number of cycles increases.

Residual Interference (Resiliency)-The residual interference, or springback, of the seals generally increased as percent linear compression increased (Fig. 9). The only inconsistency in this pattern occurred where the residual interference of the temperature-exposed seals at 30 percent compression was smaller than that at 25 percent compression. These specimens were temperature-exposed and compression tested at compression levels of 20,25, or 30 percent. It is possible that in exposing the seal to $1900{ }^{\circ} \mathrm{F}$ at 30 percent compression, the Inconel X-750 wires that make up the spring tubes in the seals were subjected to more plastic deformation than the seals that were exposed at 25 percent compression. After removal from the furnace and the test fixture, this could have caused the spring tubes in the specimens tested at 30 percent to have more permanent set and less resiliency than those tested at 25 percent compression.

Although there was a minor inconsistency among the residual interference measurements, the trend that was clearly evident in the results shown in Table 4 and Fig. 9 was that a great deal of permanent set occurred during $1900^{\circ} \mathrm{F}$ exposure of the $6 \mathrm{pcf}$ seals. At each compression level, the residual interference, or springback, of the temperature-exposed seals was only 20 to 30 percent of that for the as-received seals. As discussed previously, most of this loss of resiliency is believed to be due to permanent set that occurred in the Inconel X-750 spring tube during temperature exposure testing. In the as-received seal, the spring tube contributes significantly to the resiliency of the seals.
The as-received 6 pcf and 9 pcf seals had almost identical residual interference results at 20 percent compression. Although the 9 pcf seals had a denser core of Saffil batting than the $6 \mathrm{pcf}$ seals had, this did not result in a more resilient seal design for the 20 percent compression level.

No specific design requirement was established for seal resiliency before these tests were conducted. No detailed 3-D finite element analysis of the rudder/fin seal area had been done at the time of writing to quantify the anticipated changes in seal gap size during re-entry of the $X-38$ vehicle. The change in the size of the seal gaps during the heating cycle will be minimal because the rudders have floating fittings and attachments that were designed to compensate for thermal expansion differences between the rudder and fin structures around the seals. Based on the above and limited hand calculations, designers believe that the remaining resiliency though small is adequate for a single-use life. Any permanent set that occurs in the seals during a mission becomes inconsequential when the seals are replaced before the next mission.

Contact Width-The contact width increased for the $6 \mathrm{pcf}$ seal design in both the as-received and temperatureexposed conditions as the amount of linear compression was increased (Table 4). This shows that even after temperature exposure the seals continued to spread and flatten out as they experienced larger amounts of compression. In each test, the footprint pattern left on the pressure sensitive film after a compression cycle was solid and continuous. This indicates that during a flow test 


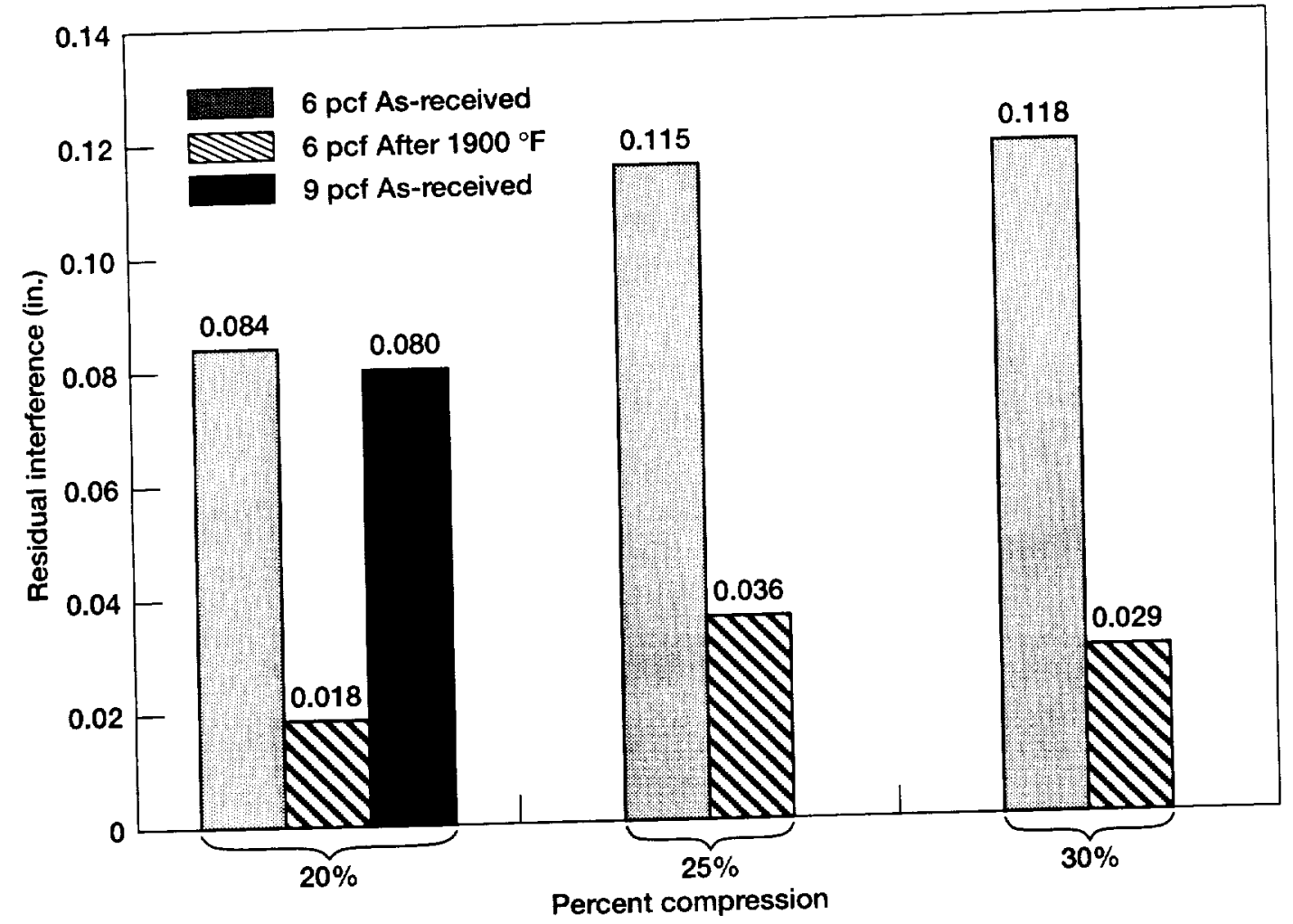

Figure 9.-The effect of temperature exposure, seal type, and compression level on seal residual interference (resiliency).

continuous contact is made between the walls of the flow fixture and the seal, minimizing leakage past the specimen.

The contact width at each compression level was larger for the as-received 6 pcf seals than it was for the temperature-exposed 6 pcf seals. After temperature exposure, the seals were less flexible and less compressible causing their contact widths to be narrower than those of the as-received seals. The contact width for the as-received 9 pcf seal at 20 percent compression was slightly larger than that of the as-received 6 pcf seal at the same compression. This difference is seen as negligible, though, as it is less than 10 percent.

Unit Load (Load per Unit Inch)/Preload/Seal Stiffness-The amount of unit load (or load per unit inch), seal preload (or footprint contact pressure), and seal stiffness increased as the amount of linear crush was increased on both the as-received and temperature-exposed 6 pcf seals (Table 4 ). Although the temperature-exposed seals were noticeably stiffer and less flexible to the touch than the as-received seals, the unit loads and preloads were lower for the temperature-exposed seals. The unit loads for the temperature-exposed seals were only 40 to 60 percent of those for the as-received seals. Preloads for the temperature-exposed seals were about 55 to 75 percent of those for the as-received seals. These observations are put in perspective using Fig. 8 and Table 4 . Seal stiffness is calculated as the slope through the final two data points at the maximum amount of compression. Seal stiffness after $1900^{\circ} \mathrm{F}$ exposure is 1.5 times higher than that of the as-received seal specimens at the design point of 20 percent compression. This shows that even though the unit loads and preloads are lower for the temperatureexposed seals, they are stiffer than the as-received seals at the same amount of compression.

The loss of load per unit inch can be explained by the loss of resiliency in the temperature-exposed seals. During the temperature exposure tests, the seals took a permanent set and assumed an elliptical cross section. When these specimens were compression tested, the starting point for the displacement measurements was set where an asreceived seal with its full circular diameter would make contact with the moving plate of the test fixture. Having taken a large permanent set, these specimens were not in contact with the moving plate at this point. The moving plate went through almost $0.1 \mathrm{in}$. of the $0.124 \mathrm{in}$. compression ( 20 percent compression) before contacting the specimen during the first load cycle (Fig. 8). After contacting the moving plate, loads were applied to the temperature-exposed specimens but at a lower level than in the as-received seals. In contrast, loads were applied to the as-received specimens throughout the first load cycle of the test. 


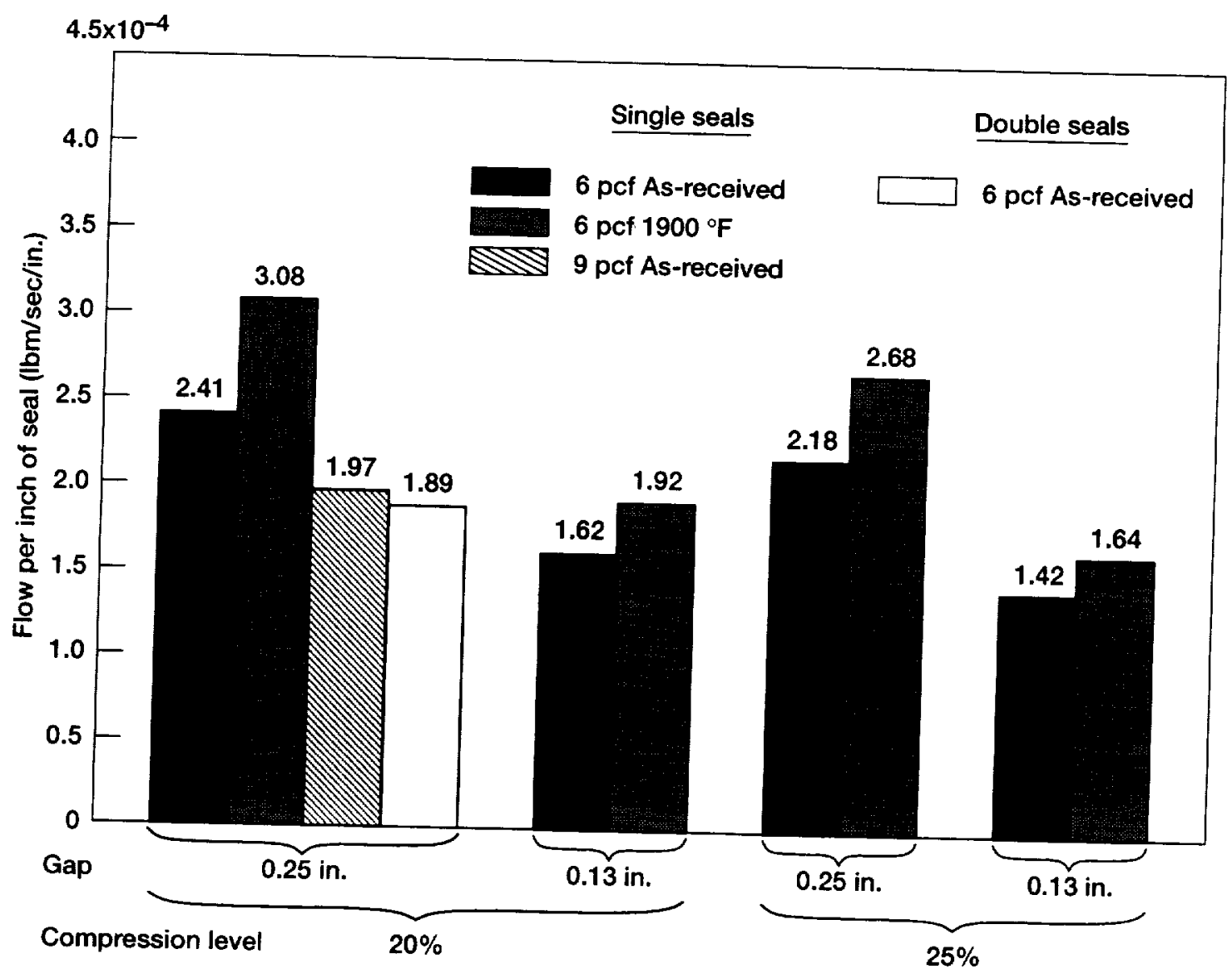

Figure $10 .-$ The effect of temperature exposure, seal type, gap size, and compression level on seal
flow, $\Delta P=56$ psf.

The temperature-exposed seals were stiffer than the as-received seals due to changes that occurred to the Inconel $\mathrm{X}-750$ spring tube during the $1900^{\circ} \mathrm{F}$ exposure. It is anticipated that during thermal exposure, permanent set of the wires deformed them and pinched them over each other in the loops that form the spring tube. Furthermore, it is anticipated that the spring tube wires oxidized causing them to become rougher. These two phenomena combined to make it harder for the wires in the loops of the spring tube to pass over each other and increased the stiffness of the temperature-exposed seals.

The stiffness of the as-received 9 pcf seals at 20 percent compression was 1.35 times higher than that of the as-received 6 pcf seals (Table 4). The 9 pcf seals also had a higher load per unit inch and preload than the $6 \mathrm{pcf}$ seals at this compression level. This was due to the denser core of Saffil batting in the 9 pcf seals. Whereas the denser core made the 9 pcf stiffer than the 6 pcf design, it did not add to the resiliency of these seals, as discussed earlier.

Comparison to Goal-While compressed between the sealing surfaces of the rudder and the fin, the seals should not put a load of more than 5 pounds perinch of seal on the Shuttle thermal tiles that make up the sealing surfaces. For this application, the seals are to be installed at approximately 20 percent compression with a nominal 0.25 -in. gap between the surfaces of the rudder and fin. The results in Table 4 show that for all compression levels tested, the unit loads are below $5 \mathrm{lb} / \mathrm{in}$. of seal. The maximum seal preload, or contact pressure, that was measured was 6.45 psi for the as-received 6 pcf seal at 30 percent compression. Even at this high level of compression, the pressure that would be applied to the tiles would be seven times lower than the flatwise tensile strength of 46 psi for the tiles and nine times lower than the compression strength (Table 1). For all compression levels, the unit loads and preloads for the temperature-exposed 6 pcf seals were even lower than for the as-received seals. The results of these compression tests indicate that both the 6 pcf and 9 pcf seals meet the seal load requirements established for the rudder/fin seal application.

\section{Flow Test Results}

Flow rates for the $6 \mathrm{pcf}$ design in the as-received and after $1900^{\circ} \mathrm{F}$ exposure conditions and for the $9 \mathrm{pcf}$ design in the as-received condition are summarized in Fig. 10. This data is shown at a pressure differential of $56 \mathrm{lbf} / \mathrm{ft}^{2}$ at 


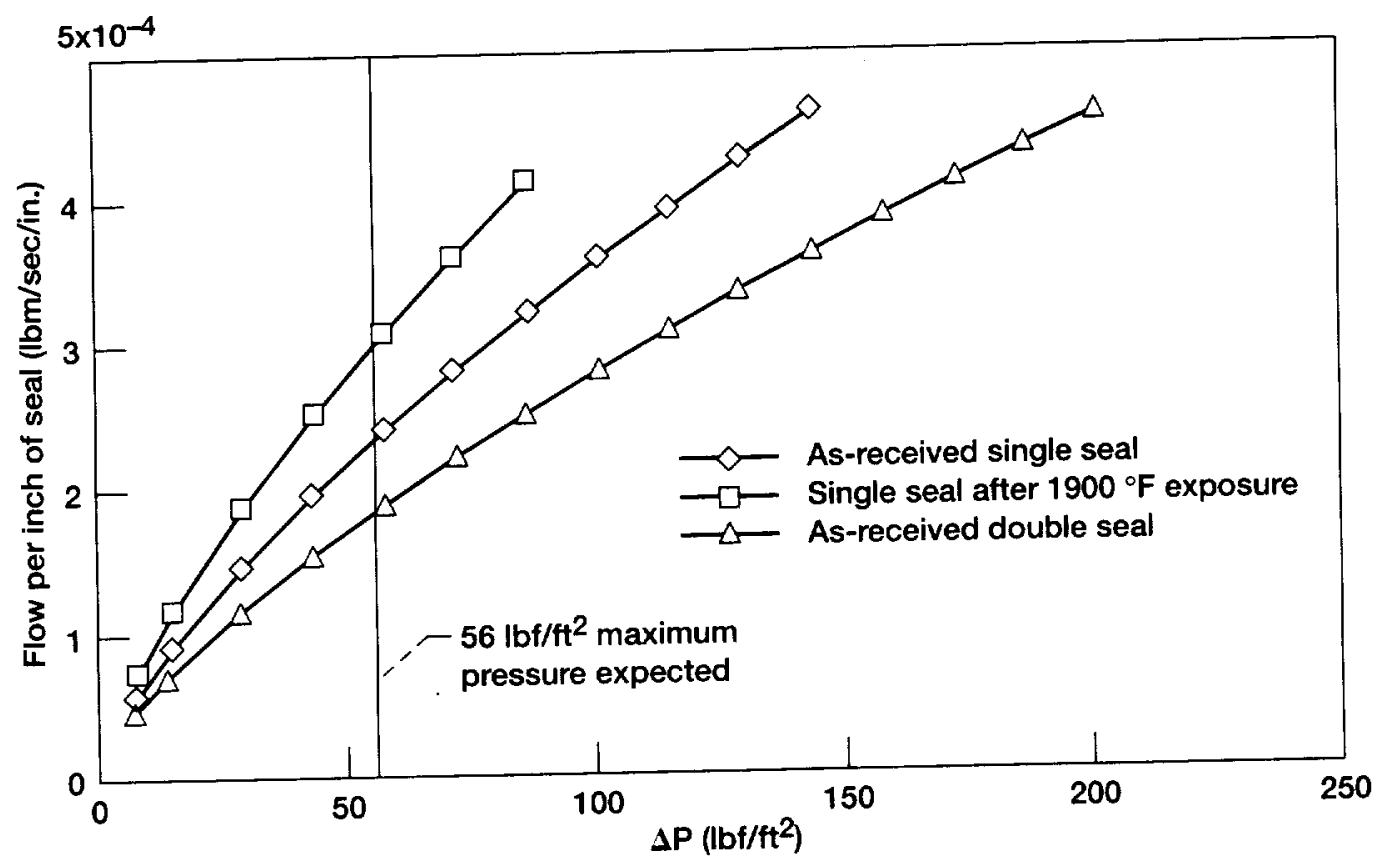

Figure 11.-Flow versus pressure data for single 6 pcf seals (as-received and after $1900^{\circ} \mathrm{F}$ temperature exposure) and for double 6 pcf seals (as-received) at $20 \%$ compression with gap of 0.25 in.

room temperature. The results show an average flow rate for two tests for the single seal tests done at 20 percent compression with a 0.25 -in. gap. The remaining flow rates shown in Fig. 10 are for single tests at each different combination of variables including the double seal test performed on the 6 pcf as-received seals. Only single tests were performed for these test conditions because of the limited amount of seal material available for testing.

Effect of Compression Level and Gap Size-As shown by the flow results, flow rates decreased with higher compression levels. Specimens tested at 25 percent compression had lower flow rates than those tested at 20 percent compression for a given gap size. This is to be expected as the act of compressing these seals closed the gaps and flowpaths in their porous structures and allowed less flow to pass through them. Similarly, reducing the gap size from 0.25 in. to 0.13 in. also lowered the amount of flow through the seal. This is also an expected outcome because a reduction in gap size decreased the flow area through the seal and further limited the amount of seal that was in the flowpath. Note, however, that cutting the seal gap roughly in half did not halve the flow rate. For the as-received and temperature-exposed 6 pcf seals, reducing the gap size from 0.25 to 0.13 in. while keeping the same compression level only lowered the flow to 61 to 67 percent of the 0.25 -in. gap flow rates. A possible explanation for this is that a fixed amount of flow is passing through both the sheath of the seal and through the seal-to-wall interfaces that does not scale with gap size.
Effect of Temperature Exposure-Temperature exposure tests were only performed on the 6 pcf design (Fig. 10). For each combination of compression level and gap size that was tested, flow rates were higher for the seals that went through the $1900^{\circ} \mathrm{F}$ exposure before being flow tested. Figure 11 presents flow versus pressure data for the $6 \mathrm{pcf}$ seal in the as-received and after temperature exposure conditions at pressures of 0 to $144 \mathrm{lb} / \mathrm{ft}^{2}$ ( $144 \mathrm{psf}=1 \mathrm{psi})$. This figure shows the typical shape of the flow versus pressure curves for these seals and emphasizes the higher flow rates for the temperature-exposed seals.

The most likely sources for higher flow results in the temperature-exposed seals were the loss in load per unit inch and the small contact footprint width. Note from Table 4 that the load per inch of the thermally exposed 6 pcf seals was about 40 to 60 percent of that for the as-received seals. Lowerunit loads combined with narrower contact widths (less seal material against the wall) lead to higher flow rates through the sealing contact.

Nextel 312 fibers are coated with an organic sizing that acts to lubricate the fibers to facilitate the braiding process. When exposed to high temperatures, this sizing burns off but leaves the ceramic fibers intact. Any sizing that was on the ceramic fibers burned off during the $1900^{\circ} \mathrm{F}$ thermal exposure. This made the temperatureexposed seals slightly more porous than the as-received seals and would have allowed slightly more flow to pass through them. 
Effect of Seal Type and Double Seal-Single seal tests were performed on both the $6 \mathrm{pcf}$ and 9 pcf seals at 20 percent compression with a 0.25 -in. gap. Flow rates through the $9 \mathrm{pcf}$ seal were 18 percent lower than those for the 6 pcf design under these conditions (Fig. 10). As mentioned previously, the main difference between these two seal designs is the density of the Saffil batting in their cores. The $9 \mathrm{pcf}$ design has a core in which the batting is packed at $9 \mathrm{lb} / \mathrm{ft}^{3}$ compared to $6 \mathrm{lb} / \mathrm{ft}^{3}$ for the $6 \mathrm{pcf}$ design. The denser core of the $9 \mathrm{pcf}$ design blocked more flow than that of the $6 \mathrm{pcf}$ design and resulted in lower flow rates.

Flow rates through double 6 pcf as-received seals were about 22 percent lower than those for a single $6 \mathrm{pcf}$ seal (see Figs. 10 and 11 ). The addition of a second seal into the flow path reduced flow rates, but it did not cut the flow in half. This type of behavior in multiple-seal flow tests was observed previously by Steinetz, et al. ${ }^{4}$

Comparison to Preliminary Flow Goal-Early in the rudder/fin seal design phase, designers proposed a preliminary flow goal of $4.2 \times 10^{-5} \mathrm{lbm} / \mathrm{sec}$ per inch of seal at a pressure of $56 \mathrm{lbf} / \mathrm{ft}^{2}$ based on a permeability of $1 \times 10^{-11} \mathrm{~m}^{2}\left(1.08 \times 10^{-10} \mathrm{ft}^{2}\right)$. (For a definition of porous media permeability see Kaviany ${ }^{8}$.) The measured flow rate for a single $6 \mathrm{pcf}$ as-received seal was $2.41 \times 10^{-4} \mathrm{lbm} /$ sec per inch of seal at $56 \mathrm{lbf} / \mathrm{ft}^{2}$ pressure, or about 5.7 times the preliminary flow goal. The measured flow rate for the double 6 pcf as-received seal was 22 percent less at $1.89 \times 10^{-4} \mathrm{lbm} / \mathrm{sec}$ per inch of seal at $56 \mathrm{lbf} / \mathrm{ft}^{2}$ pressure, or about 4.5 times the preliminary flow goal.

Based on the current investigations, the authors recognize the need for additional analyses and tests. Though the thermal analyses described herein provide a good basis to initiate design work, the authors recognize the need to perform a more detailed thermal analysis that would include flow through the seal. Using the flow rates measured herein one can reassess the maximum seal and attachment temperatures to determine if they are within limits. If these temperatures are within limits the flow goal can be raised. If the temperatures exceed the seal or attachment temperature limits then modifications to the seal to increase flow resistance (e.g., addition of flow restricting liners in the seal) will be considered and tested. In summary, data collected from the current investigations will be combined with future analyses and tests such as flow, arc jet, and scrubbing tests to make the final seal selection.

\section{Wear Resistance/Life}

In the rudder/fin seal application for the X-38, the seals will be attached to the rudder and compressed between the sealing surfaces of the rudder and the fin. Because the seals will be moved over the sealing surfaces during actuation of the rudder, they must be durable and robust enough to resist wear and still perform their sealing function while not applying too large of a load to the Shuttle tiles on the sealing surfaces. Prior to the re-entry mission, rudder actuation will be tested by moving the rudders through their full range of motion of \pm 12 degrees of rotation. This will move the seals off of the shelf of the fin while they are still in their as-received condition. They will tend to expand and spring back according to the amounts shown in Table 4. Based on the results of tests performed herein, the seals have adequate resiliency to re-engage the shelf and perform their sealing function. The seals also must not be compromised by the "scissoring" action and shear forces they will be subjected to in moving on to and off of the shelf. Planned scissoring/scrubbing tests will be used to investigate seal performance. Rudder actuation and seal scrubbing must not cause large loads on the rudder drive motor. To prevent the rudder drive motor from stalling, designers selected a motor that can easily overcome any resistive torque that the seals could impart to the system.

Rudder actuation helps control the $\mathrm{X}-38$ vehicle during its return from orbit. While the rudder/fin seal assembly is going through re-entry heating, the seals are rotated from the flush outboard to the flush inboard position, a range of \pm 8 degrees of rotation (Figs. 2 and 4 ). At the peak temperatures of re-entry the seals will be in the flush outboard position. The seals are never moved off of the shelf of the fin during this part of the re-entry cycle. In later stages of the flight after the seals go through the maximum heating cycle, they must accommodate the full rudder/fin deflection of \pm 12 degrees. Portions of the seals will be moved off of the fin shelf during these later stages of re-entry.

It is anticipated that if any damage occurs to the seals, most would take place in the Nextel 312 outer layers that cover the spring tube. While not the most durable type of ceramic fiber, Nextel 312 has been shown to have relatively good abrasion resistance. ${ }^{9}$ Seals that are used in the rudder/fin seal application will only be subjected to a relatively low number of scrubbing cycles over the sealing surfaces. The seals are also only expected to last for one reentry mission of the X-38 vehicle. Because they will be replaced after each mission, any damage that the seals experience during a mission would not affect subsequent missions.

\section{Seal Requirements for X-38 versus Future Reusable Re-Entry Vehicles}

The seal requirements for the X-38 vehicle are different from those of future reusable re-entry vehicles in several ways. The most obvious difference is that seals in the X-38 are expected to be replaced after each mission while those for future reusable re-entry vehicles would likely be required to be reusable for hundreds of missions. Reusable seals will 
need to be wear resistant to endure scrubbing against the sealing surfaces and to allow for multiple missions without being replaced. They will also need to be more resilient after repeated temperature exposures. The loss of resiliency after temperature exposure that was found for the seal designs examined in this study most likely would not be acceptable for reusable applications.

The control surface seals for the X-38 are expected to be used at much higher temperatures ( $\left.1900^{\circ} \mathrm{F}\right)$ than similar seals that are used as elevon and body flap seals in the Space Shuttle. These Shuttle seals are generally used at temperatures less than $1500^{\circ} \mathrm{F}$. Seal designs for future reusable re-entry vehicles will need to endure temperatures similar to those of the X-38 seals, if not higher. These high temperature seal applications will most likely have to be composed entirely of ceramic components. Most metals cannot endure the high temperatures that the seals will experience in these applications without causing the seals to lose resiliency. The seal designs in this study took on a large permanent set after temperature exposure due mostly to permanent deformation of the Inconel X-750 spring tube. Requirements for higher temperatures and reusability in future re-entry vehicles will necessitate that novel seal designs are developed that exhibit low flow rates and remain resilient and wear resistant for multiple missions.

\section{Summary and Conclusions}

NASA is currently developing the $\mathrm{X}-38$ vehicle that will demonstrate the technologies required for a crew return vehicle (CRV) for the International Space Station. This vehicle will serve both as an ambulance for medical emergencies and as an evacuation vehicle for the manned space station. The $X-38$ control surfaces require seals to limit hot gas ingestion and transfer of heat to underlying low-teniperature structures to prevent over-temperature of these structures and possible loss of the vehicle. NASA JSC and GRC are working together to develop the seals that are to be used in the rudder/fin interfaces of the $\mathrm{X}-38$. The main objective of the current study was the characterization of baseline designs for these seals.

Two seal designs that are used in a variety of locations on the Space Shuttle were examined as baseline seal designs for the $X-38$ rudder/fin seals. Designated as the $6 \mathrm{pcf}$ and $9 \mathrm{pcf}$ designs, the main difference between them was in the density of Saffil batting material that was used as the core of the seals $\left(6 \mathrm{lb} / \mathrm{ft}^{3}\right.$ versus $\left.9 \mathrm{lb} / \mathrm{ft}^{3}\right)$. A thermal analysis was done on the rudder/fin seal assembly based on representative heating rates on the windward surface of the rudder/fin area. Temperature exposure tests were done on the $6 \mathrm{pcf}$ seal design in a compressed state in a tube furnace to simulate $1900^{\circ} \mathrm{F}$ peak seal temperatures predicted by the thermal analysis. Room temperature compression tests were performed to determine load versus linear compression, preload, contact area, stiffness, and resiliency characteristics for the as-received and temperature-exposed seals. Flow tests were conducted on the seals under ambient temperature conditions to examine their leakage characteristics at different compression levels and gap sizes both in the as-received condition and after temperature exposure. Based on the results of the current tests, the following conclusions are made:

1. Exposure of the 6 pcf seal design in a compressed state in a tube furnace at $1900^{\circ} \mathrm{F}$ for seven minutes resulted in permanent set and loss of resiliency in these seals presumably due to yielding of the Inconel X-750 spring tube. Because of the single-use life requirement for these seals, the permanent set is not anticipated to negatively effect X-38 rudder/fin performance.

2. Unit loads and contact pressures for the as-received 6 pcf and 9 pcf designs and for the temperature-exposed 6 pcf design were below the $5 \mathrm{lb} / \mathrm{in}$. and 10 psi limits. Low unit loads and contact pressures are required to limit the loads on the Shuttle thermal tiles that the seals are in contact with in the rudder/fin location.

3. The flow rate for an as-received 6 pcf double seal was $1.89 \times 10^{-4} \mathrm{lbm} / \mathrm{sec}$ per inch of seal, or about 4.5 times the preliminary flow goal. It is recommended that a more detailed seal thermal analysis including flow through the seal be performed to assess the impact of this higher flow rate on key structural temperatures.

4. Final seal selection will be made based on the results of the current investigations and future planned analyses and flow, arc jet, and scrubbing tests.

\section{$\underline{\text { References }}$}

1. Bilstein, R.E., Orders of Magnitude: A History of the NACA and NASA, 1915-1990, NASA SP-4406, 1989, pp. 84-85.

2. Nestler, D.E., "An Engineering Analysis of Reattaching Shear Layer Heat Transfer," AIAA Paper 72-717, June 1972.

3. Steinetz, B.M., Adams, M.L., Bartolotta, P.A., Darolia, R., and Olsen, A., "High Temperature Braided Rope Seals for Static Sealing Applications," Journal of Propulsion and Power, Vol. 13, No. 5, 1997, pp. 675-682.

4. Steinetz, B.M. and Adams, M.L., "Effects of Compression, Staging, and Braid Angle on Braided Rope Seal Performance," Journal of Propulsion and Power, Vol. 14, No. 6, 1998, pp. 934-940. 
5. $\quad$ Kattus, J.R., “Inconel X-750," Aerospace Structural Metals Handbook, Vol. 4, Article 4105, Metals and Ceramics Information Center, Battelle Labs, Columbus, OH, 1990.

6. $3 M$ Nevtel Ceramic Fiber Technical Notebook, 3M Ceramic Fiber Products, St. Paul, MN, July 1997.

7. Gordon, M.P., "Space Shuttle Orbiter Thermal Protection System Processing Assessment Final Report,” Rockwell Florida Operations, May 1995, Appendix C.
8. Kaviany, M., Principles of Heat Transfer in Porous Media, $2^{\text {nd }}$ Edition, Springer-Verlag New York, Inc., New York, NY, 1995, pp. 17-18.

9. Dellacorte, C. and Steinetz, B.M., "Relative Sliding Durability of Candidate High Temperature Fiber Seal Materials," NASA TM-105806, August 1992. 


\section{REPORT DOCUMENTATION PAGE}

Form Approved

OMB No. $0704-0188$

Public reporting burden for this collection of information is estimated to average 1 hour per response, including the time for reviewing instructions, searching existing data sources, collection of information. including suggestions for reducing this burden, to Washington Headquarters Send comments regarding this burden estimate or any other aspect of this Davis Highway, Sulte 1204, Arlington. VA 22202-4302, and to the Office of Management and Budget, Paperw. Dit Reduct fon Project (0704-0188), Wand Reports, 1215 Jefferson

\begin{tabular}{l|l|l} 
1. AGENCY USE ONLY (Leave blank) & 2. REPORT DATE
\end{tabular}

\begin{tabular}{|l|l|l} 
& July 2000 & $\begin{array}{c}\text { 3. REPORT TYPE AND DATES COVERED } \\
\text { Technical Memorandum }\end{array}$ \\
\hline 4. TITLE AND SUBTITLE & 2
\end{tabular}

5. FUNDING NUMBERS

Rudder/Fin Seal Investigations for the X-38 Re-Entry Vehicle

6. AUTHOR(S)

Patrick H. Dunlap, Jr., Bruce M. Steinetz, and Donald M. Curry

7. PERforming ORGanization NAME(S) AND ADDRESS(ES)

National Aeronautics and Space Administration

John H. Glenn Research Center at Lewis Field

Cleveland, Ohio 44135-3191

8. PERFORMING ORGANIZATION REPORT NUMBER

$E-12384$

9. SPONSORING/MONITORING AGENCY NAME(S) AND ADDRESS(ES)

10. SPONSORINGMONITORING AGENCY REPORT NUMBER

National Aeronautics and Space Administration

Washington, DC 20546-0001

NASA TM-2000-210338

AIAA-2000-3508

\section{SUPPLEMENTARY NOTES}

Prepared for the 36th Joint Propulsion Conference and Exhibit cosponsored by AIAA, ASME, SAE, and ASEE, Huntsville, Alabama, July 16-19, 2000. Patrick H. Dunlap, Jr. and Bruce M. Steinetz, NASA Glenn Research Center and Donald M. Curry, NASA Johnson Space Center. Responsible person, Patrick H. Dunlap, Jr., organization code
5950, (216) 4.33-6374.

12a. DISTRIBUTION/AVAILABILITY STATEMENT

Unclassified - Unlimited

Subject Category: 37

Distribution: Nonstandard

This publication is alailable from the NASA Center for AeroSpace Information. (301) 621-0390.

13. ABSTRACT (Maximum 200 words)

NASA is currently developing the X-38 vehicle that will be used to demonstrate the technologies required for a crew return vehicle (CRV) for the Inkernational Space Station. The X-38 control surfaces require high temperature seals to limit hot gas ingestion and transfer of heat to underlying low-temperature structures to prevent over-temperature of these structures and possible loss of the vehicle This paper preicents results for thermal analyses and flow and compression tests conducted on as-received and thermally exposed seals he the ruduer/fin location of the X-38. A thermal analysis of the rudder/fin dual seal assembly based on representative heating rates on compressed state at $1900^{\circ} \mathrm{F}$ rudder/fin area predicted a peak seal temperature of $1900^{\circ} \mathrm{F}$. The temperature-exposed seals were heated in a determine load predicted peak temperature. Room temperature compression tests were performed to ture-exist preload, contact area, stiffness, and resiliency characteristics for the as-received and temperafor the seals uere rudder/fin location. Measured designs examined in this study are expected for a double seal were about 4.5 times higher than the preliminary seal flow goal. The seal Tests performed herein this application.

14. SUBJECT TERMS

Seals; Flow; Design; Test; Re-entry vehicle

15. NUMBER OF PAGES

22

16. PRICE CODE

$\mathrm{A} 03$

\section{OF REPORT}

Unclassified

18. SECURITY CLASSIFICATION OF THIS PAGE

Unclassified
19. SECURITY CLASSIFICATION OF ABSTRACT Unclassified

NSN 7540-01-280-5500 



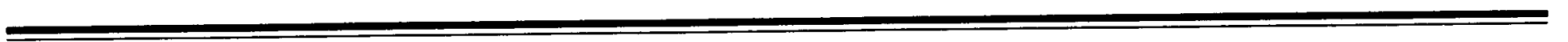

